\title{
Discussion on the Transition of Land Utility and Land Resources Management
}

\author{
Wu Xin \\ Shanxi University of Finance and Economics, 030006
}

Keywords: land utilization, land resources, transition, influence relation

\begin{abstract}
With 9.6 million square kilometers of land area, our country is endowed with abundant land resources. Because human beings cannot survive without land, the utilization of land resources plays a vital role in the development of human beings. In recent years, with the rapid development of Chinese economy, damage to the environment and land resources has also been intensified, making precious land resources become less and less. Therefore, to improve the efficiency of land resources in China has become an important subject in the current economic development of our country. This paper probes into the transition of land utilization and the management of land resources, hoping to help strengthen the management of land resources and improve the efficiency of land resources.
\end{abstract}

\section{Introduction}

Since the reform and opening up, social economy of our country has made rapid development. However, the increase of population, occupation of cultivated land area and destruction of land resources by industrialization have all caused the pressure of land resources in our country to be greater, therefore, to strengthen the management of land resources and transition of land utilization have become important issues in our country. It is necessary for us to seriously analyze related issues of land utilization and land management, and find ways to alleviate the pressure of land resources in our country, so as to ensure the rapid development of our social economy.

\section{Land Resources Management and Transition of Land utilization}

\subsection{Overview of Land Resources Management}

Land resources management refers to the relevant government departments manage the utilization of relevant land resources based on relevant laws and regulations through the adoption of related measures. In order to strengthen the management of land resources, government departments concdrned should actively take various law, administrative measures or advanced technology as well as develop relevant supervision system to ensure the implementation of management measures of land resources. Nowadays, the management system of land resources in our country mainly includes land utilization management system and land expropriation system, which can provide important system guarantee for the relevant government departments to carry out land management and promote the smooth progress of land management. The survival of mankind cannot be separated from land, since people depend on land for their food, clothing, shelter and transportation. Therefore, strengthening the management of land resources and improving the utilization efficiency of land resources play a vital role in promoting our country's economic development and improve people’s living standards.

\subsection{Overview of Transition of Land Utilization}

The transition of land use refers to the change in the mode of utilizaiton of land resources, which is based on the change of economic system and alters the form of land utilization with the transform of economic system. At present, the utilization efficiency of land resources in our country has been continuously promoted, and the government departments concerned have made effective use of land resources through continuous planning of land resources which have effectively promoted the transition of land resources utilization. In China, the traditional use of land resources is mainly 
manifested in the use of arable land, forest land and grassland. People plant food crops through the use of cultivated land, obtain wood resources through the use of woodland, put out to pasture and develop animal husbandry through the use of meadow. This form of utilization of land resources in a very long period of time is in line with the situation of our country, and provides an important guarantee for the economic development of our country. However, with the deepening development of China's reform and opening up, the economic level of our country has been continuously improved and the original land utilization mode can no longer meet the needs of the development of the times, therefore, the transition of land use is an inevitable requirement of sustainable economic development in China.

\section{Relationship between Land Utizition Transition and Land Resources Management}

\subsection{Influence of the Policy of Returning Cropland to Forest}

As an important policy of land utilization transition in China, returning cropland to forest has had an important impact and becomes a vital measure of land resource management in China. For a long time before the beginning of our country, in order to meet the needs of daily life, people had to increase the area of cultivated land for the planting of food crops, which led to the forced deforestation of a large area of forests, and conversion of large areas of woodland to arable land. With large areas of forests being cut down, the ecological environment of nature has also been greatly damaged with increasingly serious desertification, frequently occurring sandstorms, loss of a large number of soil and water, haze weather, etc. These environmental problems seriously affect people's daily life, cause serious harm to people's physical health, and even endanger people's personal safety. In order to solve the above problems, our country put forward the policy of returning cropland to forest, ensuring the area of forest land, improving the ecological environment, and giving people a fresh and green living environment.

\subsection{Influence of Cultivated Land Protection Policy}

With the development of our economy, industrialization has also made great progress. With the progress of industrialization, urbanization has also got rapid development. However, the development of industrialization and urbanization will further encroach on cultivated land. The development of industrialization requires the construction of new factories, and the expansion of urban scale also requires more housing. These are important reasons leading to the continuous decrease of cultivated land area in our country. Therefore, our country has put forward the policy of cultivated land protection, in order to realize the effective utilization of land resources, provide guarantee for our country's grain production, realize the reuse of land resources, and ensure our country's economy to develop continuously and rapidly.

\subsection{Influence of Land Transition Policy}

Nowadays, the policy of land transition in our country mainly includes two aspects. One is the contract management transiton of agricultural land and the other one is the transition of collective construction land. With the rapid development of China's economy, the construction of urbanization has also made outstanding achievements, which leads to a large number of rural population flocking to cities. The development of this trend directly affects the living environment in rural areas, greatly reducing the population of vast rural areas, especially the young and middle-aged, most of whom would choose to work and live in cities, leaving the vast amount of arable land in the countryside uncultivated. This kind of phenomenon has promoted the contract management transition of rural land. It is advantageous to form a large area of cultivated land in rural areas and thus provides an important prerequisite for the realization of agricultural mechanization. This large-scale mechanized agricultural production is also the direction of agricultural development, which can improve the speed of land circulation by taking relevant measures. It is necessary for relevant departments to strengthen the management of land transiton market and make it develop towards standardization which can effectively promote the sustainable development of agriculture in China and provide 
important safeguard for the realization of our country's agriculture modernization.

\subsection{Impact of Land Resources Management Policy}

The transition of land utilization cannot be separated from the support of land management policy. Therefore, a sound land management policy is an important guarantee for the realization of land utilization transiion. It is vital to combine the development trend of our country's social economy, proceed from reality to explore the experience constantly from the practice, and thus make a set of perfect land resources management policy according to the actual situation of each region. Perfect land resources management policy can effectively promote the efficiency of utilization of land resources transition, and greatly improve the speed of land transition, so that our country's land resources can be effectively utilized. At present, the policy of land resource management in our country mainly includes the following points. First, intensive land use system. It is mainly aimed at the control of the utilization efficiency of our country's land resources, and puts forward related request to the land use scale of land resources, therefore, as an important management system, the intensive land use system will help our country's land resources to get reasonable planning, and ensure the effective use of land resources, so that the industrial land in our country will be concentrated towards high-tech zones, and the agricultural land will be concentrated on the industrial land ${ }^{[1]}$. Second, land system of urban-rural dual system. Land management method in China stipulates that the non-agricultural construction cannot use the land owned by the rural collectives. To a certain extent, the agricultural land is protected from illegal encroachment, thus ensuring the scale of rural land. However, to some extent, this regulation has brought adverse effects to the development of rural economy. Therefore, we should pay attention to the reform of rural land to ensure the normal progress of rural land circulation. Third, rural land policy. The main content of rural land policy is the policy of farmers' transition of land management rights. The main implementation purpose of rural land policy is to promote farmers to transfer their own land use rights. Farmers are also encouraged to transfer their land use rights to large agricultural contractors, large farms, large enterprises or large-scale farms in rural areas in the form of leases. In this way, rural land will be changed from a scattered management mode to a large-scale management mode, and the large-scale management of rural land can be realized by the use of related large-scale machinery, thereby enhancing work efficiency and speeding up the process of agricultural modernization. This transtion mode of rural land changes the property rights of rural land and can effectively promote the transfer of land use.

\subsection{Influence of Economic Means of Land Management}

With the rapid development of social economy in China, in order to realize the effective management of land resources, we should strengthen the application of economic means of land management. The use of economic means of land management will guide the normal development of land use activities, which has become one of the important means of macro-control in China, and contains two important aspects, on the one hand, land price and on the other hand, land rent. Through the application of economic means of land management, the management efficiency of land resources in China can be improved, and the development of land transformation and utilization can also be promoted. In the process of concrete implementation, government is capable of reducing the occupation of cultivated land by collecting the tax of cultivated land possession, so that the area of cultivated land can be guaranteed. It promotes the input of land units to land, improves the intensification of land use, and promotes the transformation of land use in China by means of agricultural funds and loans ${ }^{[2]}$.

\subsection{Impact of Land Resources Engineering}

There are many technologies related to land resource engineering, including system engineering technology, land planning and land management. The technology of land resource engineering involves many subjects, such as the subject of agriculture, engineering and management. In order to effectively realize the transition of cultivated land utilization, we cannot be separated from the support of high standard farmland construction technology, comprehensive control of desertification 
land technology and other related technologies. At present, there are still some unreasonable factors of land utilizaiton in our country, such as low utilization efficiency of rural arable land, low unit output value, problems of land use structure in cities and so on. In order to solve these problems, we can adopt relevant engineering technology of land resources to manage land resources effectively. Therefore, in the process of land resources management, we are required to emphasize on the management of land resource. The governance of land resources is also a form of land use transition. The management of land resources will adjust the structure of agricultural land, expand the area of agricultural land, and change the original scattered land use patterns to facilitate the use of large-scale machinery, thereby improving the efficiency of land use. Strengthening the application of land resource engineering technology helps to improve the quality of land, such as the improvement of saline-alkali land, the improvement of decertified land, and so on. All these can effectively enhance the efficiency of land resources use in our country, increase the area of cultivated land in China and increase the output value of agriculture.

\section{Conclusion}

In China's vast land area, we must meet the needs of production and life of 1.3 billion people. Therefore, it is particularly important to strengthen the rational use of land resources and to realize the efficient management of land resources in China, which is also the important foundation that ensures our country economy develops at a high speed. With the development of the times and the change of social economy, our management mode of land resources should conform to the trend of the development of the times, make adjustment constantly, explore relevant methods in practice, and actively improve the traditional land management mode, so as to ensure the effective implementation of land resources management in China, and better realize the efficient use of land resources.

\section{References}

[1] Wang Xueying. Tentative Analysis of Land Utilization Transition and Land Resources Management [J]. Resource Conservation and Environmental Protection, 2018, (02): 100.

[2] Liu Haiyan. Analysis of Land Utilization Transition and Land Resources Management [J]. Inner Mongolia Coal Economy, 2018, (01): 22-23.

[3] Yang Qian. Analysis of Land Utilization Transition and Land Resources Management [J]. Sichuan Cement, 2017, (11): 160.

[4] Li Echuan. Brief Discussion on Land Utilization Transition and Land Resources Management [J]. Research on Urban Construction Theory (Electronic Version), 2017, (06): 61-62.

[5] Li Xiujin. Exploration of Land Use Transition and Land Resources Management [J]. China Housing Facilities, 2018, (04): 24-25.

[6] Yang Yu, Luyang. Discussion on Land Use Transition and Land Resources Management [J]. Building Materials and Decoration, 2016, (35): 145-146. 